\title{
National background is associated with disparities in initiation and persistence to statin treatment in subjects with diabetes in Denmark
}

\section{Helena Dominguez ${ }^{*}$, Tina Kenn Schramm², Gunnar Hilmar Gislason ${ }^{3}$, Mette Lykke Norgaard ${ }^{3}$, Jakob Raunsø ${ }^{3}$, Steen Zabell Abildstrøm ${ }^{4,5}$, Lars Kober ${ }^{2}$, Henrik Enghusen Poulsen ${ }^{5,6,7}$ and Christian Tobias Torp-Pedersen ${ }^{3,7}$}

Department of Cardiology, Herlev Hospital, Copenhagen University, Herlev, Denmark

2 The Heart Center, Rigshospitalet, Copenhagen University Hospital, Copenhagen, Denmark

${ }^{3}$ Department of Cardiology, Copenhagen University Hospital Gentofte, Hellerup, Denmark

${ }^{4}$ National Institute of Public Health, University of Southern Denmark, Copenhagen, Denmark

${ }^{5}$ Clinical Pharmacology Q7642, Rigshospitalet, Copenhagen, Denmark

${ }^{6}$ Department of Clinical Pharmacology, Bispebjerg Hospital, Copenhagen, Denmark

7 Faculty of Health Sciences, University of Copenhagen, Denmark

\section{Edited by:}

Colin H. Macphee, GlaxoSmithKline, USA

\section{Reviewed by:}

Christos Katavolos, Good Samaritan Hospital, USA

Snorri Bjorn Rafnsson, Hellenic Health

Foundation, Greece

*Correspondence:

Helena Dominguez, Cardiology Department S105, Research Unit,

Herlev Hospital, Copenhagen

University, DK-2900 Hellerup,

Denmark.

e-mail: hd@heart.dk
Background: To investigate the effects of statin use over the last 10 years among diabetic patients who initiated glucose-lowering medications (GLMs) in Denmark. Methods: we identified all Danish citizens 30 years and older who claimed their first GLM between 1997 and 2006, with follow-up until 2007. Use of medications, national background, income, and hospitalizations were obtained by cross-linkage of national registries in Denmark. We analyzed factors related to initiation and interruption of statin treatment. The analyses included country of birth, citizenship and, as proxy for ethnic origin, we constructed variables based on both the subjects and on their parent's country of birth. Countries were grouped as Denmark, Western countries, Eastern countries, and Africa. Results: the cohort included 143,625 subjects. Compared with persons of Danish origin, the initiation of a statin medication during follow-up was significantly lower among patients of nonDanish origin: Odds ratio for subjects of Eastern origin 0.61 [Cl $0.49-0.76$ ] and 0.37 for subjects of African origin, [Cl 0.24-0.59], both $p<0.001$. The risk of interrupting statin treatment once it had been initiated was also higher in these groups (hazard ratio 2.03, [Cl 1.91-2.17] for Eastern subjects and 1.94, [Cl 1.63-2.32] for African subjects, both $p<0.0001)$. Combination of ethnic parameters to refine identification of the cohort led to the same conclusions as the analysis based only on country of birth or citizenship respectively. Conclusion: diabetes patients of African and Eastern origin in Denmark have less chance of being treated with a statin than those of western and Danish origin despite similar access to the Danish health care system.

Keywords: statins, diabetes, epidemiology, registries

\section{INTRODUCTION}

Ethnic background has been demonstrated to have a profound effect on cardiovascular health parameters in North-American (Benner et al., 2002; Kaplan et al., 2004; Hertz et al., 2007; Cooper et al., 2009; McWilliams et al., 2009) and European epidemiological studies (Peters et al., 2009). In North-American studies, it has been demonstrated that even when differences in risk profiles such as socioeconomic status are equalized, clinical outcomes are still influenced by differences in ethnic background for African-Americans (Mayberry et al., 2000; Trivedi et al., 2006; Hozawa et al., 2007) and for Mexican Americans (Hertz et al., 2007). Nevertheless, ethnicity is a complex concept composed of biological and cultural elements that change over time. Therefore, it has been recently stressed the importance of defining parameters of ethnicity that give an appropriate understanding of variations in clinical outcomes by ethnicity and help issuing health policies and planning (Lee, 2009; Mladovsky, 2009; Rafnsson and Bhopal, 2009).

Statin treatment is recommended by international guidelines for almost all subjects with diabetes (NCEP, 2001; Ryden et al., 2007). This recommendation has resulted in an increased use of statins over the years (Dominguez et al., 2009). Given the increasing size of the diabetic population (Christensen et al., 2009) it is important to identify subgroups that do not adhere to guideline recommendations, for which efforts can be targeted to improve this adherence.

Danish national registries provide a unique opportunity to elaborate proxy markers for ethnic background by combining family composition for a given individual.

Thus we have performed this study comparing different ethnic background parameters on initiation and persistence in treatment with statins among new users of glucose-lowering medications (GLMs) in Denmark between 1997 and 2006.

\section{MATERIALS AND METHODS}

The study is based on cross-linkage of nationwide registries. All residents in Denmark are assigned a unique and permanent personal civil registration number at the Central Office of Civil Registration which enables cross-linkage of registries on the individual level (WHO, 2007). From the data of the Central Office of 
Civil Registration it was possible to perform ethnic grouping by identifying place of birth of an individual and his/her parents, citizenship and residence, as explained in detail below. Additionally, household income was recorded. The Danish National Patient Registry keeps records on all hospital admissions since 1978. Each admission is registered with one primary diagnosis, and if appropriate one or more secondary diagnoses, according to the International Classification of Diseases, the 8 th revision until 1994 (ICD-8) and the 10th revision (ICD-10) from 1994 (WHO, 2004). Since 1995 all claimed prescriptions from pharmacies in Denmark have been registered in the Danish Registry of Medicinal Products Statistics. Drugs are classified according to the international anatomical therapeutical chemical (ATC) system, and the registry also includes information on date of dispensing, dosage, quantity dispensed, and the affiliation of the physician issuing the prescription.

Danish national registries are centralized in Statistics Denmark where each individual civil registration number is encrypted by substituting it with another number that is the same in all registries, thereby allowing cross-linkage of encrypted data. Access to the data is granted to researchers upon registration in Danish registry. The protocol was reviewed by the Danish Ministry of Interior and Health and by the Danish Agency for Science, Technology, and Innovation.

The study cohort comprised all persons who claimed a prescription for a GLM as a proxy for diabetes diagnosis between 1997 and 2006. Persons who had purchased GLMs during 1996 were excluded. We then analyzed whether these persons subsequently claimed statins or not, hence including current statin users, with follow-up until the end of 2007. The period of days covered by a purchase of a statin was calculated based on the pack size purchased, and assuming an average dosage of one daily tablet, as we have described in previous studies (Gislason et al., 2006; Dominguez et al., 2009).

Subjects who had been hospitalized with a myocardial infarction as a primary diagnosis (ICD codes I21 or I22 and ICD-8 code 410 for myocardial infarction before 1994) in the 19 year period before inclusion were identified as "previous myocardial infarction." A prior stroke was identified in an analogous manner (ICD codes I63-I66 and IDC-8 code 432-436 for stroke before 1994). Occurrences of myocardial infarction or stroke during the study period were included as co-morbidities of interest. If a person had suffered both MI and stroke, the latest event prior to GLM initiation was included in the analyses.

Ethnicity parameters were analyzed combining data collected in the Central Office of Civil Registration. Country of birth and citizenship respectively were considered as simple ethnicity parameters. Furthermore, we sought to approach the effect of cultural legacy in our cohort by constructing a refined ethnicity proxy that we called "country of origin" based on the parent's country of birth for a given individual (Figure 1). Accordingly, persons with a parent born in Denmark and holding Danish citizenship were categorized as being "of Danish origin" regardless of the place of birth of the given individual. Persons born in Denmark or abroad with parents not fulfilling Danish citizenship were classified as "not of Danish origin." The country of origin was determined by the mother's country of birth if

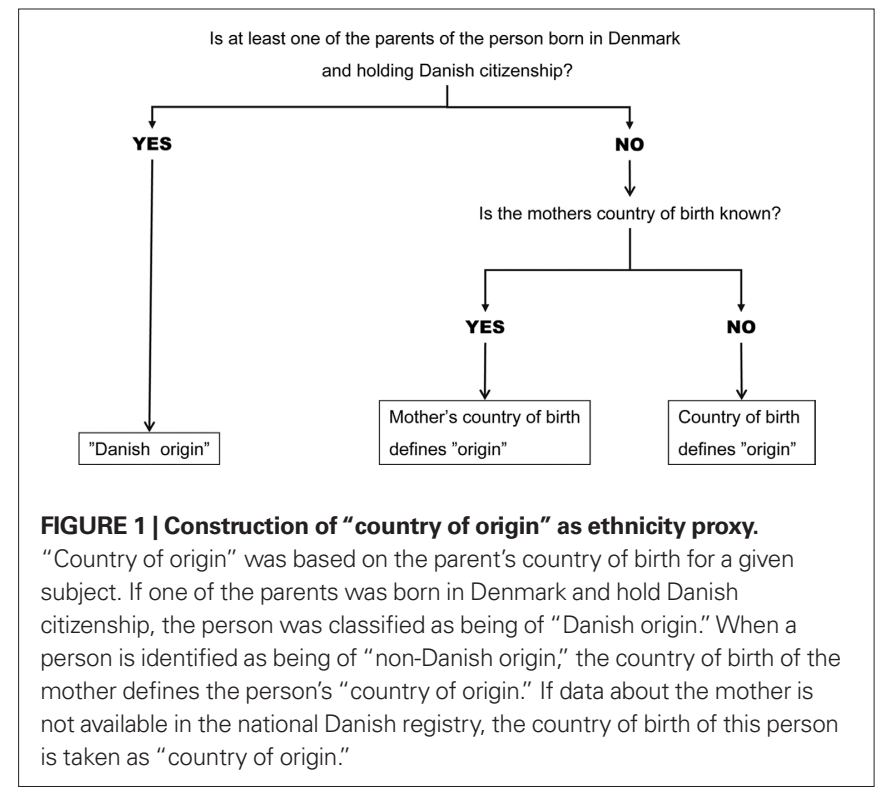

data existed, otherwise by the country of birth of the individual. Countries were grouped in four categories: (1) "Denmark"; (2) "Western countries" for European countries other than Denmark, including Baltic countries, America, and Oceania; (3) "Eastern countries" for all countries from the Asian continent, although including Turkey, and (4) "Africa" for all countries from the African continent.

To investigate secular trends over time, the 10 years follow-up was divided in three periods: (1) from 1997 to 2000; (2) from 2001 to 2003, and (3) from 2003 to 2007. Use of GLMs was assessed upto the end of 2006. Subsequent commencement of statin treatment was followed upto the end of 2007, ensuring at least 1 year follow-up for the subjects who initiated GLM during 2006. Subjects were censored at the end of follow-up or if they emigrated from Denmark, regardless whether they returned to Denmark or not.

Adherence can be defined in different ways. Most often adherence has been defined as the time-course until treatment is paused. Since many subjects who pause their medication after a myocardial infarction resume the treatment even after several months cessation (Gislason et al., 2006), we performed two analyses. Firstly we calculated the percentage of subjects receiving statins at any timepoint and secondly we analyzed the time until a break in treatment of 90 days or more occurred, as a dichotomous variable, as we have described in previous studies (Gislason et al., 2006; Dominguez et al., 2009).

This manuscript follows the strengthening the reporting of observational studies in epidemiology (STROBE) recommendations (von Elm et al., 2008). All authors have read and agreed to the manuscript as written.

\section{STATISTICAL ANALYSIS}

We performed a Cox proportional-hazards analysis to assess factors associated with initiation of statins according to ethnic origin, adjusting for year of first GLMs prescription claim (using the time period 1997 to 2000 as reference), age, sex, previous myocardial infarction, previous stroke, insulin treatment as the first anti-diabetes 
medicine and income graded in quartiles. Analyses were repeated for ethnic grouping based on citizenship and on country of birth, with the same covariates included in the models.

Model assumption for the proportional-hazard models (proportional-hazard assumption, linearity of continuous variables, and lack of interaction) were tested and found valid unless otherwise indicated.

All statistical calculations were performed SAS statistical software package, version 9.1 for UNIX servers (SAS Institute Inc., Cary, NC, USA).

\section{RESULTS}

In total, the cohort comprised 143,625 new users of GLMs from January 1st 1997 to December 31st 2006. Baseline characteristics and the distribution of the cohort according to their ethnic origin are shown in Table 1. Subjects of Eastern and African origin were younger and less likely to have a previous history of myocardial infarction and/or stroke. The highest proportion of men was found among African subjects.

The chance of ever receiving statins was 39\% lower among subjects from Eastern origin and about 63\% lower among subjects from African origin while it was 20\% lower among subjects from Western origin compared to Danish subjects (Table 2). Analyses based on birth and on citizenship as unrefined ethnic parameters yielded similar results - data not shown. For the total cohort of GLMs users, there was a progressive increase in the use of statins, with a tendency over the years to reduce ethnic differences for subjects of Western and Eastern origin but not among Africans, as depicted in Figure 2. Since European and American guidelines updates encouraged a broader use of statins in subjects with diabetes (Wood et al., 1998; NCEP, 2001), the 10 year follow-up is divided in Figure 2 in two periods from 1997 to 2001 (Figure 2A) and from 2001 to 2007 (Figure 2B). Multivariable analyses revealed no interaction between sex and the different ethnic groups on initiation of statins, or between country of origin and year of prescription.

A previous myocardial infarction or previous stroke increased the chance that GLMs users initiated statins more than twofold for myocardial infarction and by about $60 \%$ for stroke (Table 2 ). No interactions were observed in several models for ethnic origin and analyses by citizenship and by country of birth respectively yielded equivalent results (data not shown). Hence ethnic origin did not seem to influence the effect of a previous myocardial infarction or stroke on higher chance for the initiation of statins. Low income had some effect on initiation of statins with a $24 \%$ higher risk for the group with lowest income ( $p=0.02$; Table 2 ).

Between 85 and $95 \%$ of the Danish subjects who commenced treatment with statins, continued using statins throughout the following years, while a larger amount of subjects from other ethnic

Table 2 | Cox proportional analysis on the proportion of subjects who initiated statin treatment after the first claimed prescription of glucose-lowering medicine.

\begin{tabular}{|c|c|c|c|}
\hline & Hazard ratio & $95 \% \mathrm{Cl}$ & $P$ \\
\hline Age - per 10 year increment & 0.98 & $0.92-1.01$ & 0.4 \\
\hline Female sex* & 1 & & \\
\hline Male sex & 1.08 & $0.95-1.22$ & 0.4 \\
\hline $1997-2000^{*}$ & 1 & & \\
\hline 2001-2003 & 2.06 & $1.89-2.23$ & $<0.0001$ \\
\hline 2004-2006 & 2.15 & $2.04-2.26$ & $<0.0001$ \\
\hline \multicolumn{3}{|l|}{ infarction or stroke* } & \\
\hline Previous myocardial infarction & 2.89 & $2.55-3.27$ & $<0.0001$ \\
\hline Previous stroke & 1.36 & $1.14-1.62$ & 0.0006 \\
\hline GLM other than insulin* & 1 & & \\
\hline Insulin treatment & 0.63 & $0.53-0.77$ & $<0.0001$ \\
\hline \multicolumn{4}{|l|}{ COUNTRY OF ORIGIN } \\
\hline Denmark* & 1 & & \\
\hline Western countries** & 0.80 & $0.68-0.95$ & 0.009 \\
\hline Eastern countries ${ }^{*}$ & 0.61 & $0.49-0.76$ & $<0.0001$ \\
\hline Africa & 0.37 & $0.24-0.59$ & $<0.0001$ \\
\hline \multicolumn{4}{|l|}{ INCOME } \\
\hline Highest quartile* & 1 & & \\
\hline Third quartile & 0.96 & $0.83-1.12$ & 0.6 \\
\hline Second quartile & 0.89 & $0.78-1.02$ & 0.1 \\
\hline Lowest quartile & 0.76 & $0.64-0.91$ & 0.002 \\
\hline
\end{tabular}

* Reference in Cox regression analysis.

**Western countries include America, Oceania, Baltic countries, and Western Europe. Eastern countries include Asia and Turkey.

Table 1 | Distribution of the cohort of 143,625 subjects using glucose-lowering medications in Denmark in the period 1997-2006, according to ethnic origin.

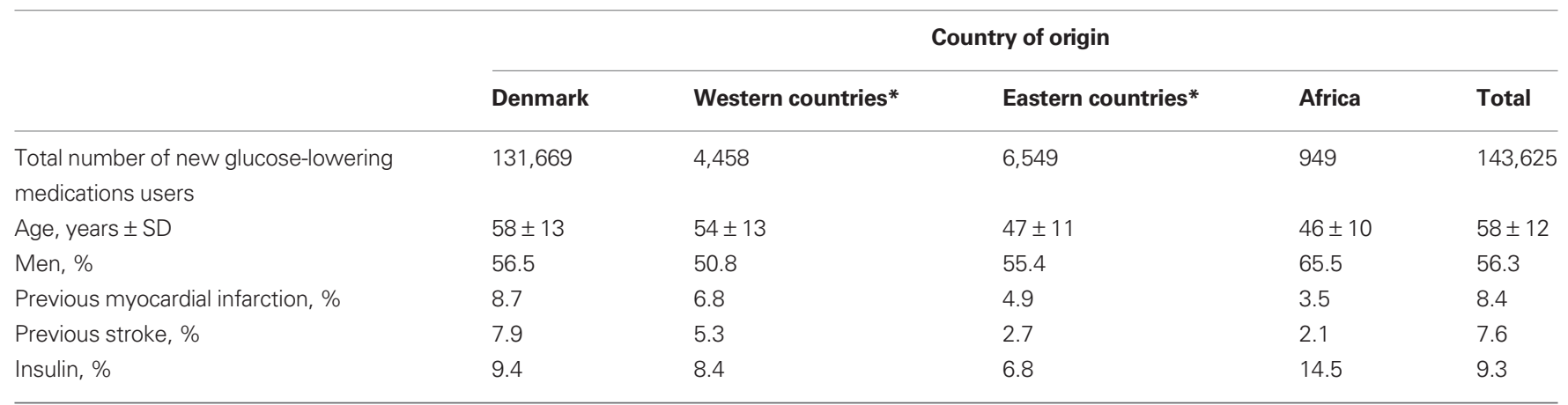

*Western countries include America, Oceania, Baltic countries, and Western Europe. Eastern countries include Asia and Turkey. 

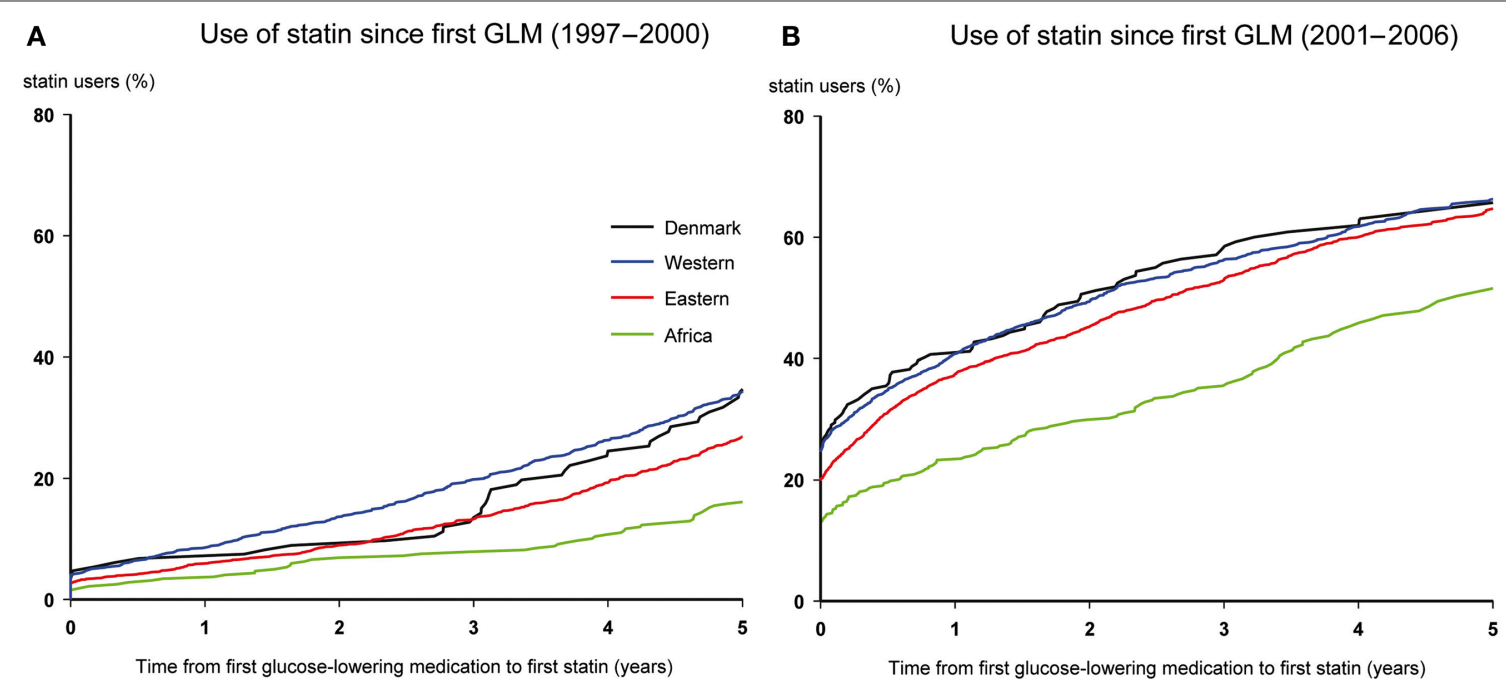

FIGURE 2 | Statin initiation among glucose-lowering medicine users 1997-2006. Kaplan-Meier plots over elapsed time from first glucose-lowering medicine (GLM) claim until the first statin claim over a 5-year follow-up period since 1997 (A) and 2001 (B) respectively.

origins discontinued statin (Figure 3). Multivariable Cox analyses were performed to elucidate which factors determined a poor longterm use of statins (Table 3 ) and demonstrated an increased risk for discontinuing statin treatment, especially among subjects of Eastern and African origin. These analyses with refined parameters for ethnic origin yielded similar results to analyses using simple parameters as country of birth and citizenship (Figure 4). Income did not seem to have a strong effect on the risk to withhold statins, with only a highest risk of $7 \%$ for discontinuation for the group with lowest income (Table 3). Multivariable analyses revealed no interaction between sex and the different ethnic groups for the risk of interrupting statin treatment.

\section{DISCUSSION}

This nationwide study reveals important ethnic inequalities in Denmark among persons who have commenced using GLMs over a 10-year period, from 1996 to 2006. Persons with Eastern and African background are identified as a high risk group since they initiate statin treatment later, to a lesser extent and are at higher risk of discontinuing statin treatment than other ethnic groups.

The main strength of the study is the completeness of data, especially regarding systematic collection of the population living in Denmark and of all diabetes subjects receiving GLMs treatment on a nationwide level. It has been claimed that ethnic parameters used in published studies are often just one such as birth place or citizenship, or they are poorly defined (Lin and Kelsey, 2000; Ford and Kelly, 2005). In a review of European studies that addresses ethnicity, it has been advocated that supplementary data should be registered to provide a more nuanced picture, such as length of stay in the country (Rafnsson and Bhopal, 2009). In our study it is possible to identify accurately whether individuals are born in Denmark and whether one of the parents is both born in Denmark and holds Danish citizenship, or not. Nevertheless, such a refined background classification did not yield stronger associations on use of statins compared to analysis with simple parameters as birthplace or

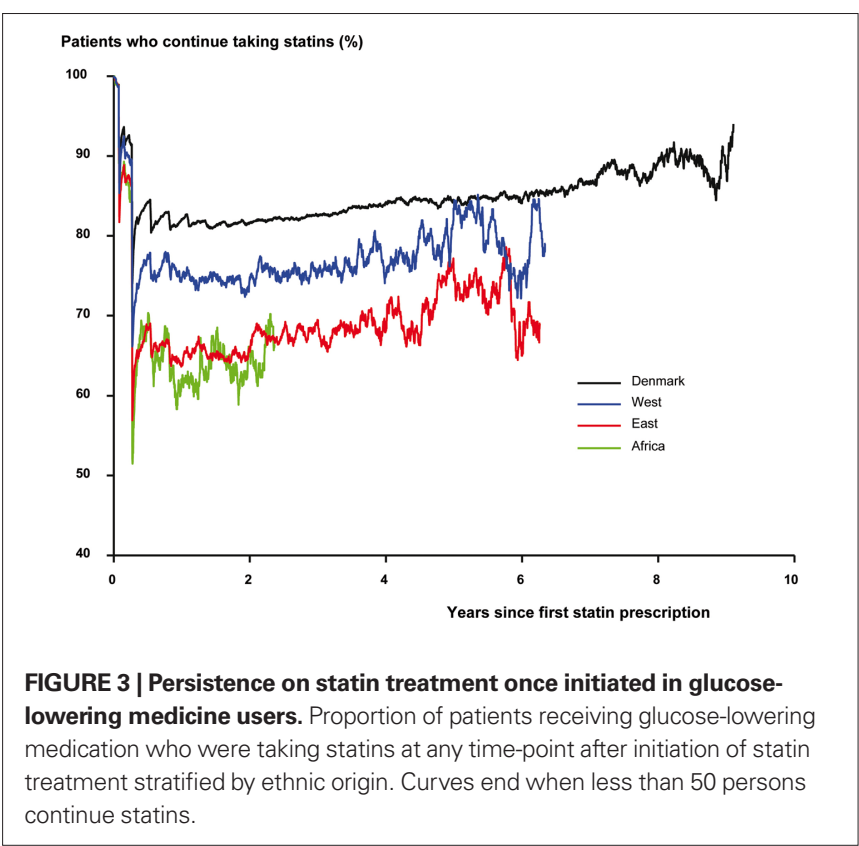

citizenship alone. By contrast, the Eastern and African populations were robustly identified in all analyses as high risk populations for lack of initiation of statins (Table 2; Figure 2) as well as for interrupting statin treatment (Table 3; Figures 3 and 4 ).

Our results are in agreement with findings in a British study that regards the use of health services among different ethnic groups (Peters et al., 2009). Our cohort of African subjects is approximately 10 years younger than the rest of the population (Table 1) which may affect the results of the analyses. Nevertheless, in a previous study it has been observed that cardiovascular risk is increased in all persons over 30 years old using GLMs (Schramm et al., 2008). Furthermore, we cannot exclude that lipid levels among GLMs users from African origin are lower, but in the atherosclerosis risk 
Table 3 | Cox proportional-hazard analysis of covariates influencing discontinuation of statin treatment for $\mathbf{9 0}$ days or more in subjects receiving glucose-lowering medication.

\begin{tabular}{|c|c|c|c|}
\hline & Hazard ratio & $95 \% \mathrm{Cl}$ & $\boldsymbol{P}$ \\
\hline Age - per 10 year & 0.85 & $0.83-0.87$ & $<0.0001$ \\
\hline Female sex* & 1 & & \\
\hline Male sex & 1.14 & $1.10-1.18$ & 0.04 \\
\hline $1997-2000^{*}$ & 1 & & \\
\hline 2001-2003 & 0.95 & $0.90-0.99$ & 0.03 \\
\hline 2004-2006 & 0.85 & $0.82-0.90$ & $<0.0001$ \\
\hline \multicolumn{4}{|l|}{ infarction or stroke } \\
\hline Previous myocardial infarction & 0.76 & $0.64-0.91$ & $<0.0001$ \\
\hline Previous stroke & 0.70 & $0.54-0.93$ & 0.004 \\
\hline GLM other than insulin* & 1 & & \\
\hline Insulin treatment & 0.92 & $0.86-0.92$ & 0.01 \\
\hline \multicolumn{4}{|l|}{ COUNTRY OF ORIGIN } \\
\hline Denmark* & 1 & & \\
\hline Western countries** & 1.13 & $1.01-1.28$ & 0.04 \\
\hline Eastern countries ${ }^{* *}$ & 2.03 & $1.91-2.17$ & $<0.0001$ \\
\hline Africa & 1.94 & $1.63-2.32$ & $<0.0001$ \\
\hline \multicolumn{4}{|l|}{ INCOME } \\
\hline Highest quartile* & 1 & & \\
\hline Third quartile & 1.08 & $0.90-1.28$ & 0.4 \\
\hline Second quartile & 1.17 & $1.00-1.37$ & 0.05 \\
\hline Lowest quartile & 1.24 & $1.05-1.46$ & 0.01 \\
\hline
\end{tabular}

* Reference in Cox regression analysis.

**Western countries include America, Oceania, Baltic countries, and Western Europe. Eastern countries include Asia and Turkey.

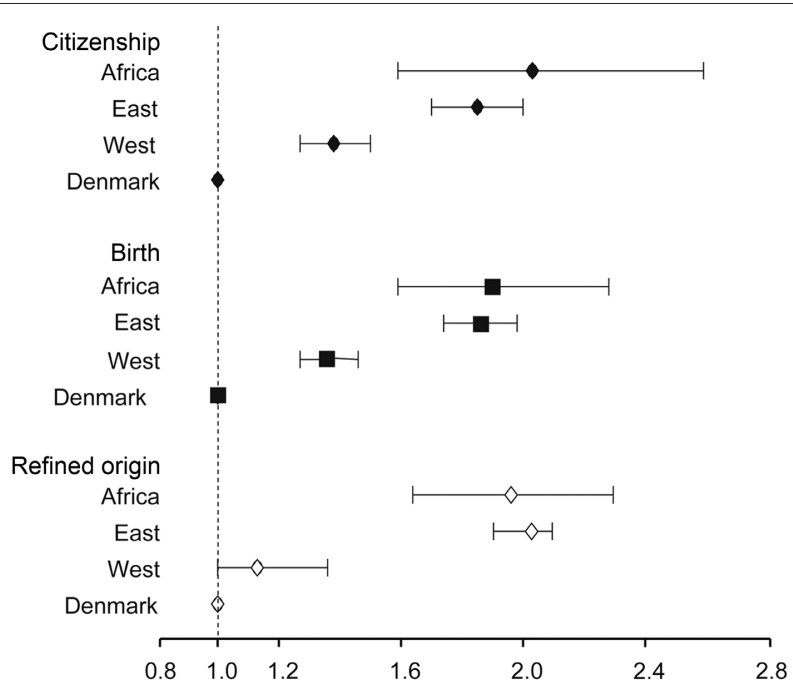

FIGURE 4 | Comparison of hazard ratios associated to use of statins according to different ethnicity parameters. Comparison of the hazard ratios obtained by Cox analysis for discontinuation of statins obtained using simple ethnic grouping by citizenship and by country of birth compared with refined grouping according to country of origin, obtained by combining individual country of birth with the parents' country of birth. in communities study (ARIC) population study of cardiovascular risk factors among African-American compared to White subjects, no differences were found in lipid levels (Hozawa et al., 2007), which is also consistent with the review by Kurian et al. of studies focusing on the African population (Kurian and Cardarelli, 2007). Even though metabolic parameters seem to differ between Eastern and Western populations (De Silva et al., 2007; Christensen et al., 2009; Likhari and Gama, 2009), it is unlikely that the subjects from Eastern countries in Denmark have less need of statins as persons from certain Eastern countries around the world have been identified as being at particularly high risk of coronary heart disease and of diabetes (McKeigue, 1989; Fischbacher et al., 2009; Gupta et al., 2009) Hence, subjects from Eastern countries with diabetes living in Denmark receive which probably inadequate statin treatment.

Socioeconomic status has previously been associated with statin initiation and persistence (Auchincloss et al., 2007; Rasmussen et al., 2007; Schneeweiss et al., 2007; Jackevicius et al., 2008; Manderbacka et al., 2008). In our study we did not find statistically significant interactions when stratifying ethnic origin by household income. The relatively little impact of income in relation to ethnic origin may be due to the general social equality in access to healthcare in Denmark, and is in accordance with studies from the US, where ethnic differences have been shown to be present while insurance coverage is the same (Trivedi et al., 2006). Even extended insurance coverage has not been sufficient to reduce ethnic disparities (McWilliams et al., 2009).

This study has some limitations that are important to emphasize. An important limitation is the lack of information on individual lipid levels. Since diabetes is a high risk factor for cardiovascular events (Haffner et al., 1998; Schramm et al., 2008), guidelines recommend low target lipid levels in all diabetic subjects (NCEP, 2001; Buse et al., 2007; Ryden et al., 2007). Most subjects need pharmacological intervention to reach these goals. Lacking knowledge on lipid levels, this study regards only use of statins, which is the first-line of medical intervention, and does not address possible indication for use of other lipid-lowering medications. Furthermore, we do not have information about subjects that were intolerant to treatment or terminated treatment due to side-effects. Nor do we have information on subjects with contraindications to treatment with statins.

It is important to consider that our ethnical grouping may carry some bias that lead to overestimation on the lack of use of statins. In spite of broad Danish reimbursement policies, we cannot discard that some subjects do purchase medications as GLM and statins in their countries of origin.

The US studies have identified limited health literacy and education (Parker et al., 2003; Sudore et al., 2006), and mistrust of the health care system (Armstrong et al., 2006; Ranjit et al., 2007) as important factors for health disparities. We cannot discard that disparities in educational level and psychosocial factors may account for the differences in statin use in our cohort. To elucidate this question requires further studies.

The advantage of using GLMs to identify diabetes subjects is that the indication for treatment is specific for diabetes subjects. Hence, this population is well-defined. Nevertheless, use of GLMs as a proxy for the diagnosis of diabetes excludes subjects who have been diagnosed as having diabetes but who are not using 
GLMs. Additionally, the exclusion of subjects who had claimed GLMs the year before 1997 does not warrant that subjects who claimed GLMs in 1997 and later on did so for the very first time. Some of these subjects may have started GLMs treatment earlier but through dieting and exercise they may have achieved control of glycemia and thereby, delayed the need for restarting GLMs until further development of diabetes. Finally, in our study it is not possible to identify type 1 and type 2 diabetes among insulin consumers.

The criteria for the diagnosis of myocardial infarction have changed throughout the observation period. The diagnosis of myocardial infarction in the National Patient Registry has proved to be valid, with a sensitivity of $91 \%$ and a positive predictive value of 93\% (Madsen et al., 2003).

In this study there are not included data on race nor self-assessment of ethnic identification (Lin and Kelsey, 2000; Ford and Kelly, 2005). Lack of data on race is probably not of central importance. Even though race-related differences in genetic manifestations exist (Lewis et al., 2008), race does not warrant biologic homogeneity as there is more genetic variation within races than among races (Bhopal and Donaldson, 1998; Goodman, 2000), rendering more importance to ethnic background. It is possible that inclusion of self-perception of ethnic background would yield other results. Nevertheless, a person can identify with multiple ethnicities to various degrees depending on personal, social, and political environment, which renders self-perception of ethnicity highly fluent

\section{REFERENCES}

Armstrong, K., Rose, A., Peters, N., Long, J. A., McMurphy, S., and Shea, J. A. (2006). Distrust of the health care system and self-reported health in the United States. J. Gen. Intern. Med. 21, 292-297.

Auchincloss, A. H., Diez Roux, A. V., Brown, D. G., O'Meara, E. S., and Raghunathan, T.E. (2007). Association of insulin resistance with distance to wealthy areas: the multi-ethnic study of atherosclerosis. Am. J. Epidemiol. 165, 389-397.

Benner, J. S., Glynn, R. J., Mogun, H., Neumann, P. J., Weinstein, M. C., and Avorn, J. (2002). Long-term persistence in use of statin therapy in elderly subjects. JAMA 288, 455-461.

Bhopal, R., and Donaldson, L. (1998). White, European, Western, Caucasian, or what? Inappropriate labeling in research on race, ethnicity, and health. Am. J. Public Health 88, 1303-1307.

Buse, J. B., Ginsberg, H. N., Bakris, G. L., Clark, N. G., Costa, F., Eckel, R., Fonseca, V., Gerstein, H.C., Grundy, S., Nesto, R. W., Pignone, M. P., Plutzky, J., Porte, D., Redberg, R., Stitzel, K. F., and Stone, N. J. (2007). Primary prevention of cardiovascular diseases in people with diabetes mellitus: a scientific statement from the American Heart Association and the American Diabetes Association. Circulation 115, 114-126.
Christensen, D. L., Witte, D. R., Kaduka, L., Jorgensen, M. E., Borch-Johnsen, K., Mohan, V., Shaw, J. E., Tabak, A. G., and Vistisen, D. (2009). Moving to an $\mathrm{HbAlc}$ based diagnosis of diabetes has a different impact on prevalence in different ethnic groups. Diabetes Care 33, 580-582.

Cooper,W.A., Thourani, V.H., Guyton, R. A., Kilgo, P., Lattouf, O. M., Chen, E. P., Morris, C. D., Vega, J. D., Vassiliades, T. A. Jr., and Puskas, J. D. (2009). Racial disparity persists after on-pump and off-pump coronary artery bypass grafting. Circulation 120, S59-S64.

De Silva, D. A., Woon, F. P., Xie, X. Y., Li Hsian Chen, C., Chang, H. M., and Wong, M. C. (2007). Metabolic syndrome among ethnic South Asian subjects with ischemic stroke and comparison with ethnic Chinese subjects: the Singapore General Hospital experience. J. Stroke Cerebrovasc. Dis. $16,119-121$.

Dominguez, H., Schramm, T. K., Norgaard, M. L., Abildstrom, S. Z., Kober, L., Jorgensen, C., Guterbaum, T. J., Poulsen, H. E., Torp-Pedersen, C., and Gislason, G. H. (2009). Initiation and persistence to statin treatment in subjects with diabetes receiving glucose-lowering medications 1997-2006. Open Cardiovasc. Med. J. 3, 152-159.

Executive Summary of the Third Report of the National Cholesterol Education

over time (Lin and Kelsey, 2000). An assessment of the effect of self-defined ethnicity may therefore require repeated questionnaires over the 10-year follow-up (Ford and Kelly, 2005), which is beyond the scope of the present study.

\section{CONCLUSION}

The Eastern and the African diabetes population receiving GLMs in Denmark receive markedly less statins than the population from Western countries compared to those of Danish origin. This is due to lower initiation rates and, when initiated, due to a higher level of discontinuation of statins. Analysis of the chances for initiation of statins and of the risk of treatment discontinuation by country of birth and by citizenship rendered the same patterns as analysis based on refined ethnic origin parameters.

\section{AUTHOR CONTRIBUTIONS}

Christian Tobias Torp-Pedersen, Tina Kenn Schramm, and Gunnar Hilmar Gislason have contributed to the analysis of the data. All authors, included them stated above have contributed to the interpretation of the results, and helped to draft the manuscript.

\section{ACKNOWLEDGMENTS}

This study has been founded by a grant from The Danish Ministry of Interior and Health. Compliance Funding (2006-13009-315) and The Danish Agency for Science, Technology and Innovation (271-08-0944).

Program (NCEP). (2001). Expert panel on detection, evaluation, and treatment of high blood cholesterol in adults (Adult Treatment Panel III). JAMA 285, 2486-2497.

Fischbacher, C. M., Bhopal, R., Steiner, M. Morris, A. D., and Chalmers, J. (2009). Is there equity of service delivery and intermediate outcomes in South Asians with type 2 diabetes? Analysis of DARTS database and summary of UK publications. J. Public Health 31, 239-249.

Ford, M. E., and Kelly, P. A. (2005). Conceptualizing and categorizing race and ethnicity in health services research. Health Serv. Res. 40, 1658-1675.

Gislason, G. H., Rasmussen, J. N., Abildstrom, S. Z., Gadsboll, N., Buch, P., Friberg, J., Rasmussen, S., Kober, L., Stender, S., Madsen, M. and Torp-Pedersen, C. (2006). Longterm compliance with beta-blockers, angiotensin-converting enzyme inhibitors, and statins after acute myocardial infarction. Eur. Heart J. 27, 1153-1158.

Goodman, A. H. (2000). Why genes don't count (for racial differences in health). Am. J. Public Health 90, 1699-1702.

Gupta,M., Braga, M. F., Teoh,H., Tsigoulis, M., and Verma, S. (2009). Statin effects on LDL and HDL cholesterol in South Asian and white populations. J. Clin. Pharmacol. 49, 831-837.
Haffner, S. M., Lehto, S., Ronnemaa, T. Pyorala, K., and Laakso, M. (1998). Mortality from coronary heart disease in subjects with type 2 diabetes and in nondiabetic subjects with and without prior myocardial infarction. N. Engl. J. Med. 339, 229-234.

Hertz, R. P., McDonald, M., Unger, A. N., and Lustik, M. B. (2007). Racial and ethnic disparities in the prevalence and management of cardiovascular risk factors in the United States workforce. J. Occup. Environ. Med. 49, 1165-1175.

Hozawa, A., Folsom, A. R., Sharrett, A. R., and Chambless, L. E. (2007). Absolute and attributable risks of cardiovascular disease incidence in relation to optimal and borderline risk factors: comparison of African American with white subjects - atherosclerosis risk in communities study. Arch. Intern. Med. 167, 573-579.

Jackevicius, C.A., Li, P., and Tu, J.V. (2008). Prevalence, predictors, and outcomes of primary nonadherence after acute myocardial infarction. Circulation 117, 1028-1036.

Kaplan, R. C., Bhalodkar, N. C., Brown, E. J. Jr., White, J., and Brown, D. L. (2004). Race, ethnicity, and sociocultural characteristics predict noncompliance with lipid-lowering medications. Prev. Med. 39, 1249-1255.

Kurian, A. K., and Cardarelli, K. M. (2007). Racial and ethnic differences 
in cardiovascular disease risk factors: a systematic review. Ethn. Dis. 17, 143-152.

Lee, C. (2009). "Race" and "ethnicity" in biomedical research: how do scientists construct and explain differences in health? Soc. Sci. Med. 68, 1183-1190.

Lewis, J. P., Palmer, N. D., Hicks, P. J., Sale, M. M., Langefeld, C. D., Freedman, B. I., Divers, J., and Bowden, D. W. (2008). Association analysis in African Americans of Europeanderived type 2 diabetes single nucleotide polymorphisms from whole-genome association studies. Diabetes 57, 2220-2225.

Likhari, T., and Gama, R. (2009). Glycaemia-independent ethnic differences in $\mathrm{HbA}(1 \mathrm{c})$ in subjects with impaired glucose tolerance. Diabet. Med. 26, 1068-1069.

Lin, S. S., and Kelsey, J. L. (2000). Use of race and ethnicity in epidemiologic research: concepts, methodological issues, and suggestions for research. Epidemiol. Rev. 22, 187-202.

Madsen, M., Davidsen, M., Rasmussen, S., Abildstrom, S. Z., and Osler, M. (2003). The validity of the diagnosis of acute myocardial infarction in routine statistics: a comparison of mortality and hospital discharge data with the Danish MONICA registry. J. Clin. Epidemiol. 56, 124-130.

Manderbacka,K., Keskimaki,I., Reunanen, A., and Klaukka, T. (2008). Equity in the use of antithrombotic drugs, betablockers and statins among Finnish coronary subjects. Int. J. Equity Health $7,16$.

Mayberry, R. M., Mili, F., and Ofili, E. (2000). Racial, and ethnic differences in access to medical care. Med. Care Res. Rev. 57(Suppl. 1), 108-145.

McKeigue, P. M. (1989). Disturbances of insulin in British Asian and white men. BMJ 299, 1161-1162.

McWilliams, J. M., Meara, E., Zaslavsky, A. M., and Ayanian, J. Z. (2009). Differences in control of cardiovascular disease and diabetes by race, ethnicity, and education: U.S. trends from 1999 to 2006 and effects of medicare coverage. Ann. Intern. Med. 150, 505-515.

Mladovsky, P. (2009). A framework for analysing migrant health policies in Europe. Health Policy 93, 55-63.

Parker, R. M., Ratzan, S. C., and Lurie, N. (2003). Health literacy: a policy challenge for advancing high-quality health care. Health Aff. (Millwood) 22, 147-153.

Peters, J., Parry, G. D., Van Cleemput, P. Moore, J., Cooper, C. L., and Walters, S. J. (2009). Health and use of health services: a comparison between Gypsies and Travellers and other ethnic groups. Ethn. Health 14, 359-377.

Rafnsson, S. B., and Bhopal, R. S. (2009). Large-scale epidemiological data on cardiovascular diseases and diabetes in migrant and ethnic minority groups in Europe. Eur. J. Public Health 19, 484-491.

Ranjit, N., Diez-Roux, A. V., Shea, S. Cushman, M., Seeman, T., Jackson, S. A., and Ni, H. (2007). Psychosocial factors and inflammation in the multiethnic study of atherosclerosis. Arch. Intern. Med. 167, 174-181.

Rasmussen, J. N., Gislason, G. H., Rasmussen, S., Abildstrom, S. Z., Schramm, T.K., Kober, L., Diderichsen, F., Osler, M., Torp-Pedersen, C., and Madsen, M. (2007). Use of statins and beta-blockers after acute myocardial infarction according to income and education. J. Epidemiol. Community Health 61, 1091-1097.

Ryden, L., Standl, E., Bartnik, M., Van den Berghe, G., Betteridge, J., de Boer, M. J., Cosentino, F., Jonsson, B., Laakso, M., Malmberg, K., Priori, S., Ostergren, J., Tuomilehto, J., Thrainsdottir, I. Vanhorebeek, I., Stramba-Badiale, M., Lindgren, P., Qiao, Q., Priori, S. G., Blanc, J. J., Budaj, A., Camm, J., Dean, V., Deckers, J., Dickstein, K., Lekakis, J., McGregor, K., Metra, M., Morais, J., Osterspey, A., Tamargo, J., Zamorano, J. L., Deckers, J. W., Bertrand, M., Charbonnel, B. Erdmann, E., Ferrannini, E., Flyvbjerg,
A., Gohlke, H., Juanatey, J. R., Graham, I., Monteiro, P. F., Parhofer, K., Pyorala, K., Raz, I., Schernthaner, G., Volpe, M. and Wood, D. (2007).Guidelines on diabetes, pre-diabetes, and cardiovascular diseases: executive summary. The task force on diabetes and cardiovascular diseases of the European Society of Cardiology (ESC) and of the European Association for the Study of Diabetes (EASD). Eur. Heart J. 28, 88-136.

Schneeweiss, S., Patrick, A. R., Maclure, M., Dormuth, C. R., and Glynn, R. J. (2007). Adherence to statin therapy under drug cost sharing in subjects with and without acute myocardial infarction: a population-based natural experiment. Circulation 115, 2128-2135.

Schramm, T. K., Gislason, G. H., Kober, L., Rasmussen, S., Rasmussen, J. N. Abildstrom, S.Z., Hansen, M. L., Folke, F., Buch, P., Madsen, M., Vaag, A., and Torp-Pedersen, C. (2008). Diabetes subjects requiring glucose-lowering therapy and nondiabetics with a prior myocardial infarction carry the same cardiovascular risk: a population study of 3.3 million people. Circulation 117 , 1945-1954.

Sudore, R. L., Yaffe, K., Satterfield, S. Harris, T. B., Mehta, K. M., Simonsick, E. M., Newman, A. B., Rosano, C. Rooks, R., Rubin, S. M., Ayonayon, H. N., and Schillinger, D. (2006). Limited literacy and mortality in the elderly: the health, aging, and body composition study. J. Gen. Intern. Med. 21 , 806-812.

Trivedi,A. N., Zaslavsky, A. M., Schneider E. C., and Ayanian, J. Z. (2006) Relationship between quality of care and racial disparities in medicare health plans. JAMA 296, 1998-2004.

von Elm, E., Altman, D. G., Egger, M., Pocock, S. J., Gotzsche, P. C., and Vandenbroucke, J. P. (2008). The strengthening the reporting of observational studies in epidemiology (STROBE) statement: guidelines for reporting observational studies. J. Clin. Epidemiol. 61, 344-349.
WHO. (2004). International Statistical Classification of Diseases, and Related Health Problems. 2. Geneva: WHO.

WHO. (2007). The WHO Collaborating Centre for Drug Statistics Methodology. ATC index with DDDs, and Guidelines for ATC classification, and DDD assignment, Oslo. Available at: http://www.whocc.no/ atc/structure_and_principles/

Wood, D., De Backer, G., Faergeman, O., Graham, I., Mancia, G., and Pyorala, K. (1998). Prevention of coronary heart disease in clinical practice: recommendations of the second joint task force of European and other societies on coronary prevention. Atherosclerosis 140, 199-270.

Conflict of Interest Statement: The authors declare that the research was conducted in the absence of any commercial or financial relationships that could be construed as a potential conflict of interest.

Received: 04 August 2010; accepted: 02 December 2010; published online: 20 December 2010.

Citation: Dominguez H, Schramm TK, Gislason GH, Norgaard ML, Raunsø J, Abildstrøm SZ, Kober L, Poulsen HE and Torp-Pedersen CT (2010) National background is associated with disparities in initiation and persistence to statin treatment in subjects with diabetes in Denmark. Front. Pharmacol. 1:142. doi:10.3389/ fphar.2010.00142

This article was submitted to Frontiers in Cardiovascular and Smooth Muscle Pharmacology, a specialty of Frontiers in Pharmacology.

Copyright (C) 2010 Dominguez, Schramm, Gislason, Norgaard, Raunsø, Abildstrøm, Kober, Poulsen and Torp-Pedersen. This is an open-access article subject to an exclusive license agreement between the authors and the Frontiers Research Foundation, which permits unrestricted use, distribution, and reproduction in any medium, provided the original authors and source are credited. 